\title{
Collision of tall vehicles due to lean
}

\author{
Alapati Sreejan \\ Email: $\underline{\text { sreejanalapati25@gmail.com }}$
}

\section{Keywords: Vehicle lean; uneven road; vehicle tilt; Roll angle; Path planning.}

\begin{abstract}
Tall vehicles like trucks and buses tend to sway about roll axis when they encounter an uneven road surface that interacts differently with different wheels. The extent of this sway is significantly more for tall vehicles so much so, they lean over a certain distance to the side. When two tall vehicles move on an uneven road adjacent to each other, this lean-over distance should be considered to steer the vehicle to avoid any collision. This paper presents this scenario and also discusses a method that relates the lean-over distance to road geometry.
\end{abstract}

\section{Introduction}

If two tall vehicles are moving alongside each other on a bumpy road, the vehicles naturally roll or sway in a transverse direction about their roll axis. Because of the extent of the roll, they possibly bump into each other if they lean as shown in Figure 1. The extent of this sway to the side of the vehicle is termed as lean-over distance in this paper. This resulting collision will be significant for tall vehicles than for shorter vehicles. A human driver can anticipate a possible collision due to roll and act to counter such an incident. However, autonomous vehicles might not have a prior estimate, as sensors mounted on the vehicle (accelerometer or gyroscopic sensor) can only record the roll angle, but they do not predict the roll angle.

Autonomy is introduced and experimented not only in cars but also trucks and buses, which have a tall body when compared to their track width. Autonomous vehicles use algorithms to construct a bounding box around the obstacle or other vehicle to bind the limits of motion. Many parameters are considered to construct a bounding box like pitch and yaw of the vehicle [1]. But, the width of the bounding box can change due to the roll of the vehicle which should be increased to accommodate lean-over. Other work shows consideration of self vehicle dynamics to record the data about the environment [2]. Several path planning techniques exist for autonomous cars [3] [4]. Both static and dynamic object detection and path planning are shown in previous papers [5]. Estimation of vertical vehicle dynamics which produce the roll, for an uneven road was studied by considering the road profile as a mathematical function [6]. Roll motion was also modelled for off-road condition [7] in earlier work, but consideration of the roll angle as a factor for collision in the transverse direction while overtaking was previously less studied. To find out the lean over distance due to roll, one has to incorporate the roll angle into vehicle dynamics. After the road surface is mapped, the equations of vehicle dynamics can be used to compute the estimated roll angle for that road. The estimation of the roll angle of the vehicle during cornering was described in earlier papers [8]. This work presents a mathematical relation between the road geometry and roll angle, thereof estimating the lean-over distance of the tall vehicle. 


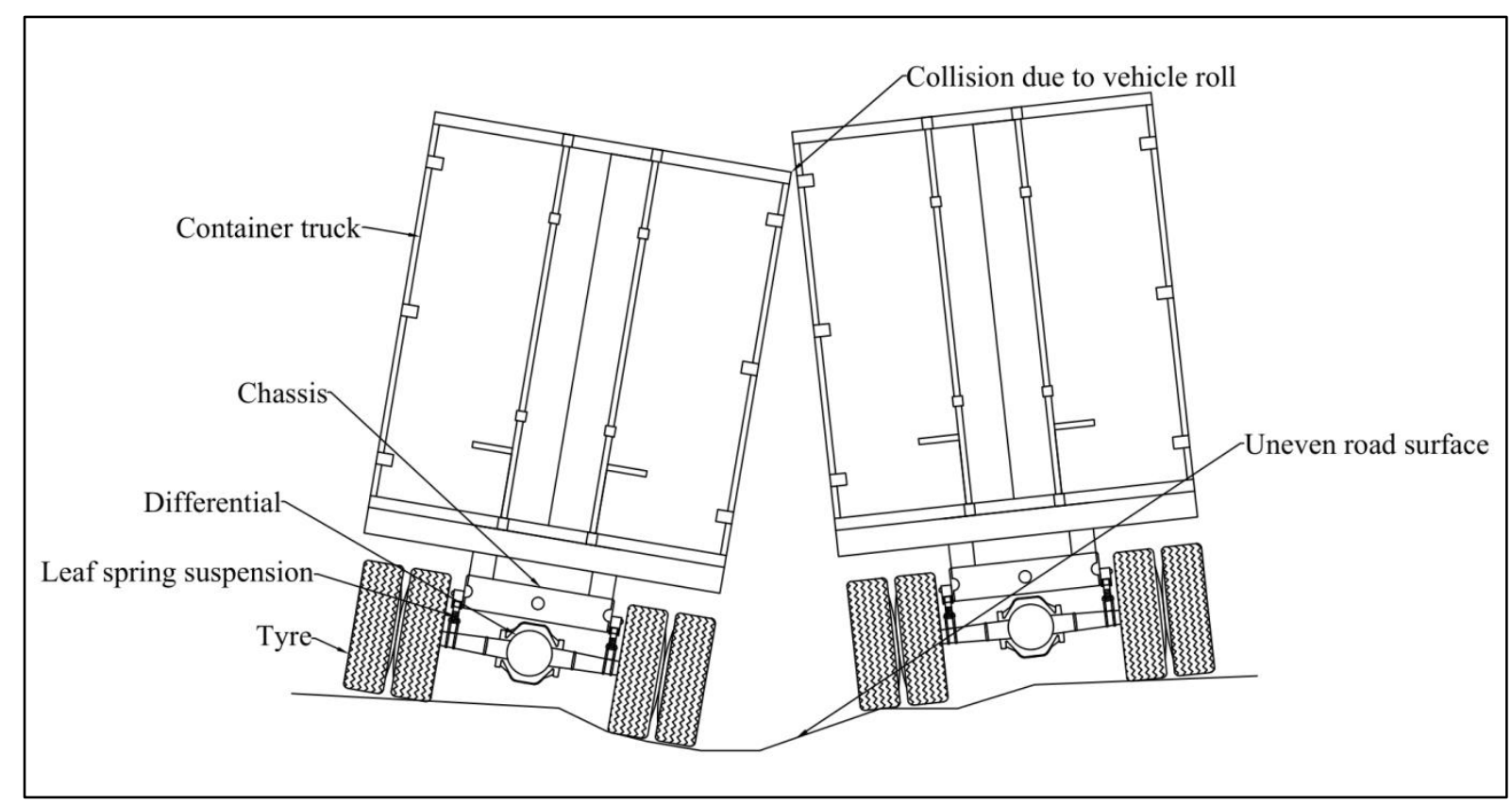

Figure 1 Lean over of tall vehicle due to body roll

Notation

\section{Physics notations}

$g \quad$ Acceleration due to gravity

$a$ Acceleration measured by sensors

$u, v \quad$ Initial and final velocity as in equations of motion

$x, \mathrm{y} \quad$ Displacement of wheel centre with time

$t \quad$ Time

$k \quad$ Spring constant

$m \quad$ Mass of wheel and axle

$M \quad$ Mass of vehicle and occupants

$F_{m} \quad$ Force due to the mass of the vehicle

$F_{a} \quad$ Force due to acceleration of the vehicle

$F_{R} \quad$ Resultant force of $F_{m}$ and $F_{a}$

$F_{R}{ }^{\prime} \quad$ Component of $F_{R}$ acting at point of contact towards the centre of the wheel

$F_{C} \quad$ Component of $F_{R}{ }^{\prime}$ responsible for compression of vehicle suspension

$C_{w} \quad$ Compression of suspension due to the weight of occupants

$C_{f} \quad$ Compression of suspension due to forces on the wheel

$C_{m} \quad$ Maximum compression possible for vehicle suspension

\section{Geometry notations}

$\varnothing \quad$ Roll angle of the vehicle

A Height of vehicle

$B \quad$ Track width of the vehicle

$S \quad$ Lean-over distance

$R \quad$ Radius of wheel

$e_{1}, e_{2} \quad$ Fraction multiplied to the radius to get the approximated point of contact

$w_{P} \quad$ Width of pothole

$d_{P} \quad$ Depth of pothole

$h_{b} \quad$ Height of bump

$r_{b} \quad$ Radius of bump

$\theta \quad$ Angle of the tangent at the point of contact for pothole/ bump

$\alpha \quad$ Angle of resultant $F_{R}$

$h_{c} \quad$ Difference in height of wheels due to compression of the suspension 
$h_{R P} \quad$ Difference in height of wheels due to road profile

$h \quad$ Difference in height on either side of the chassis causing the roll

\subsection{Significance of the Roll angle on Lean-over distance}

The lean-over distance is more if the vehicle is tall, even for the same roll angle. Because of this, more proximity has to be provided around the tall vehicle, when it is approaching another vehicle, when travelling on an uneven road, for safe steering. The required proximity for vehicles with different height and same track width are shown in Table 1 based on trigonometric relation.

Table 1 Lean-over distance of vehicle for different roll angles

\begin{tabular}{|c|c|c|c|c|}
\hline $\begin{array}{c}\text { S. } \\
\text { No. }\end{array}$ & $\begin{array}{c}\text { Wheel track } \\
\text { width }\end{array}$ & $\begin{array}{c}\text { Roll } \\
\text { angle }\end{array}$ & $\begin{array}{c}\text { Lean-over distance for a 2.5- } \\
\text { meter tall vehicle }\end{array}$ & $\begin{array}{c}\text { Lean-over distance for a 5- } \\
\text { meter tall vehicle }\end{array}$ \\
\hline 1 & 2.5 meter & $5^{\circ}$ & 0.2 meter & 0.4 meter \\
\hline 2 & 2.5 meter & $10^{\circ}$ & 0.4 meter & 0.9 meter \\
\hline 3 & 2.5 meter & $15^{\circ}$ & 0.6 meter & 1.3 meter \\
\hline
\end{tabular}

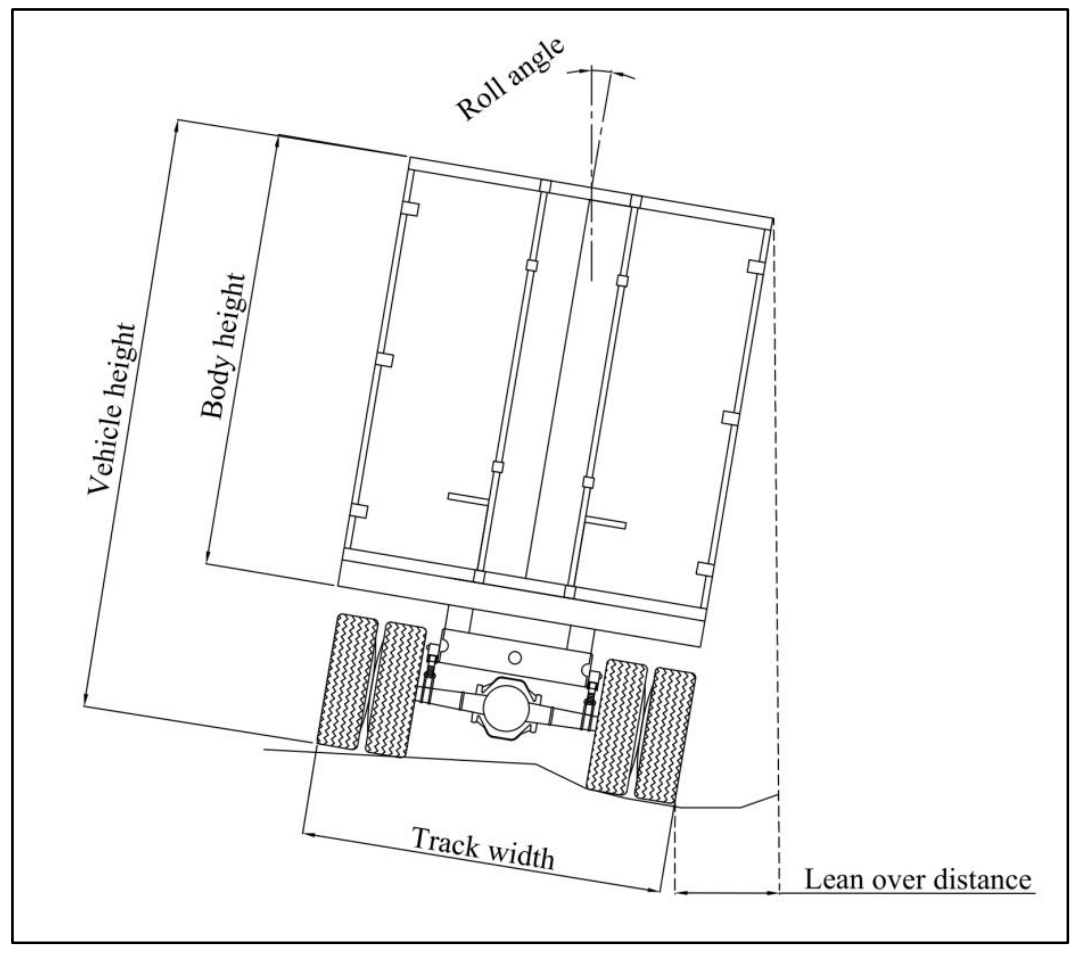

Figure 2 various parameters of a vehicle

Table 1 emphasis the extent of lean-over for roll angle in the increments of $5^{\circ}$. Even for small roll angles that are halfway to the required average safety angle in a tilt test [9], the required proximity around the vehicle is considerable. 
The mathematical equations are written by assuming the road profile is known accurately. Identifying road profile is beyond the scope of this paper, however, it is possible [10]. The equations assume a coordinate system concerning the wheel centre. Variables in the direction to the right and up are taken as positive and towards left and down are negative. Acceleration and velocity will not vary much when the wheel crosses pothole/ bump, and are assumed constant. Tyre compliance and wheel slip on road is neglected. Also, since the tyre is assumed to be non-compliant, all forces on the tyre are transferred to the suspension without loss. A quarter car model is used as an uneven road profile will interact differently on wheels. The equations are presented in an algorithmic approach, unlike the vehicle dynamics models.

\section{The equation for vehicle roll angle}

When a vehicle encounters a bump/ pothole on the road, the suspension is compressed or extended due to vertical forces. The result of this extension/ compression is a tilt of the vehicle, causing the roll. This happens only when both wheels of an axle have different proportions of extension/ compression. The pothole or bump here means the difference in height of the road profile that the wheels of an axle are about to interact. The vertical forces on suspension are dependent on the weight of the vehicle and also the speed of the vehicle. Both of these parameters are included in the estimation of the roll angle in this paper. Since this paper emphasis on tall vehicles, a leaf spring suspension is depicted.

The bump/ pothole on a road may be of different forms as shown in Figure 3 that can be small, moderate or continuous. The interaction of these features and wheel will be different. However, for a pothole, the wheel has to fall into; and for a bump, it has to rise above. So, the two scenarios are treated differently to obtain the equations.

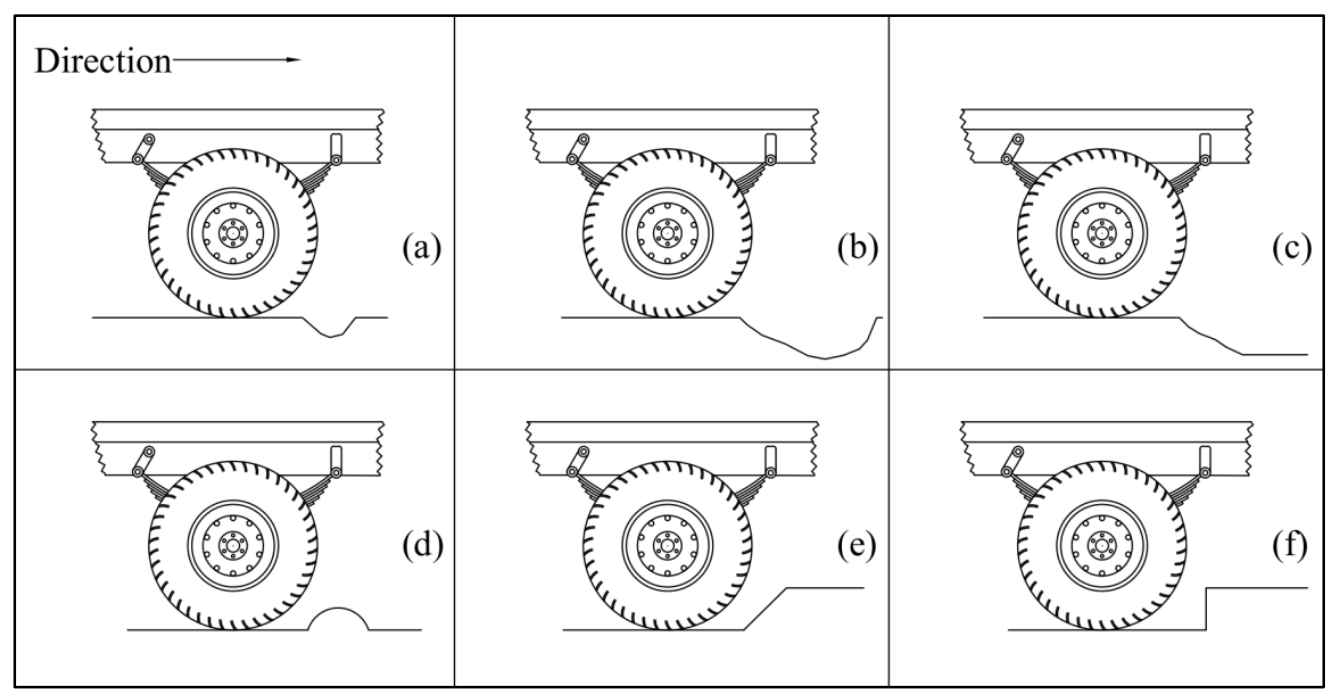

Figure 3 Different road profiles

\subsection{Interaction of the pothole with the wheel}

When a wheel encounters a pothole, the chassis of the vehicle continues to move in direction of travel due to inertia but does not have an instant reaction in the vertical direction. The suspension already in the compressed state because of the weight of vehicle and occupants is relaxed and spring extends, causing the wheel to move vertically into the pothole. So for a 
wheel that encountered a pothole, a displacement in the horizontal direction due to the velocity of the vehicle and displacement in vertical due to extension of spring exists. If the velocity of the vehicle is fast enough the wheel can completely skip the pothole, if spring extension is very less in the time vehicle crosses the pothole. All these aspects are incorporated into the equations.

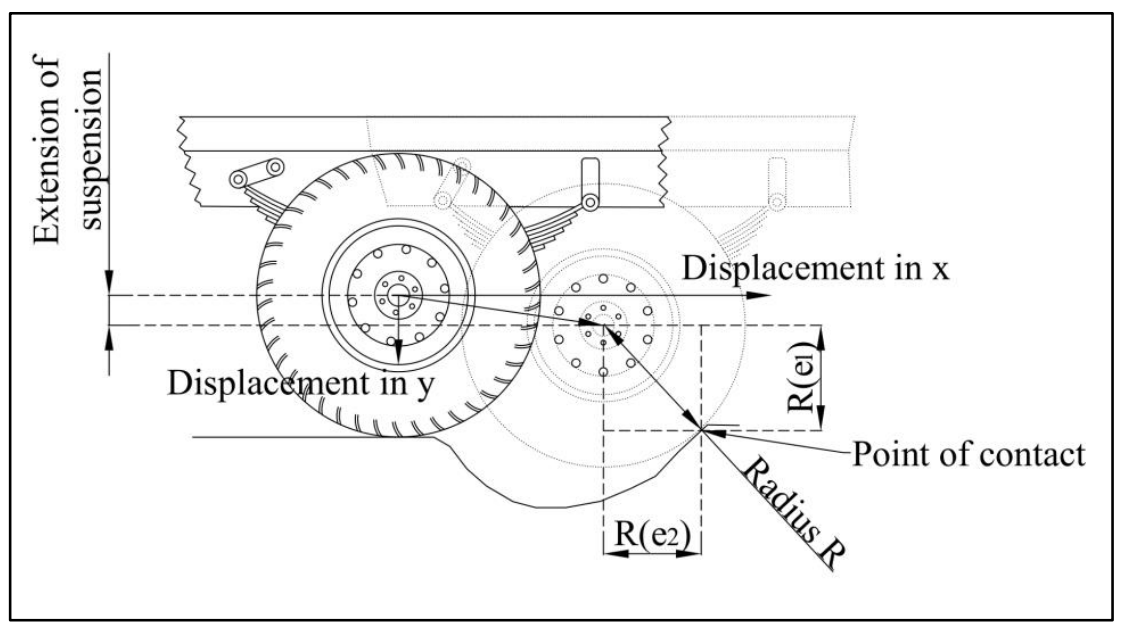

Figure 4 Point of contact for pothole

Considering the centre of the wheel as the point of interest, the respective displacements can be given from equations of motion. To these displacements, a distance value is added that will approximate the point of contact of the wheel as shown in Figure 4.

$$
\begin{gathered}
x_{\text {displacement }}=u t+\frac{1}{2} a t^{2}+R\left(e_{2}\right) \\
y_{\text {displacement }}=-\left(C_{w} \sqrt{\frac{k}{m}}\right) t-\frac{1}{2}\left(g t^{2}\right)-R\left(e_{1}\right)
\end{gathered}
$$

Proof: velocity of spring is due to stored potential energy

Formula of spring potential energy $=\frac{1}{2} \mathrm{kx}^{2}$

Where $\mathrm{k}$ is spring constant and $\mathrm{x}$ is compression of spring

Work done will be equal to the stored elastic potential energy

$$
\mathrm{F} * \mathrm{~s}=\frac{1}{2} \mathrm{kx}^{2}
$$

Also, displacement s can be written in terms of velocity

$$
\mathrm{m} * \mathrm{a} *\left(\frac{\mathrm{v}^{2}-\mathrm{u}^{2}}{2 \mathrm{a}}\right)=\frac{1}{2} \mathrm{kx}^{2}
$$

By simplifying the equation we get, $v=\left(x \sqrt{\frac{\mathrm{k}}{\mathrm{m}}}\right)$

The values $R\left(e_{2}\right)$ and $R\left(e_{1}\right)$ are in $\mathrm{x}$ and $\mathrm{y}$ directions respectively. The value of $e$ is decided based on the extension of spring and depth of pothole as shown in Table 2. If the suspension 
is extending more into the pothole, it will have a lower angle of contact and vice versa. The way extension of spring can be obtained is described in section 2.1.1.

Table 2 estimation of point of contact for pothole

\begin{tabular}{|c|c|c|c|c|c|}
\hline S. No. & Depth of pothole & Extension of spring & $\begin{array}{c}\text { Angle } \\
\text { approximated }\end{array}$ & $\begin{array}{c}\text { Value of } \mathrm{e}_{1} \\
\text { (cosine value) }\end{array}$ & $\begin{array}{c}\text { Value of } \mathrm{e}_{2} \\
\text { (sine value) }\end{array}$ \\
\hline 1 & $\mathrm{~d}$ & $1 / 3(\mathrm{~d})$ & 75 & 0.26 & 0.97 \\
\hline 2 & $\mathrm{~d}$ & $2 / 3(\mathrm{~d})$ & 45 & 0.71 & 0.71 \\
\hline 3 & $\mathrm{~d}$ & $\mathrm{~d}$ & 15 & 0.97 & 0.26 \\
\hline
\end{tabular}

Special case i:

If the width of the pothole is small compared to the radius of the wheel as shown in Figure $3(a)$, the angle of the tangent at the point of contact and y displacement can be given by following equations.

$$
\begin{gathered}
\theta=\sin ^{-1}\left(\frac{W_{P} / 2}{R}\right) \\
y_{\text {displacement }}=R-R \cos \theta
\end{gathered}
$$

Special case ii:

If the pothole is continuous as shown in Figure 3(c), the angle of the tangent at the point of contact will be zero degrees and y-displacement will be equal to the depth of the pothole.

\subsubsection{Extension of suspension}

From the $\mathrm{x}$-displacement with respect to time and knowing the width of the pothole, time taken for the vehicle to cross the pothole can be obtained. Within this time the y-displacement will give the extension of spring into the pothole.

\subsubsection{Angle of the tangent at the point of contact}

Once the point of contact is known, the angle made by the tangent of the pothole profile at the point of contact with horizontal will give the angle of contact. Because road profile is assumed to be known geometrically, the tangent angle can be calculated mathematically.

From Figure 5, the angle $\alpha$ is

$$
\begin{gathered}
\tan \alpha=\frac{F_{m}}{F_{a}} \\
\text { And, } \\
F_{R}{ }^{2}=F_{a}{ }^{2}+F_{m}{ }^{2}
\end{gathered}
$$


It should be noted that $F_{m}$ denotes the force on a single wheel but not the force due to the entire mass of the vehicle.

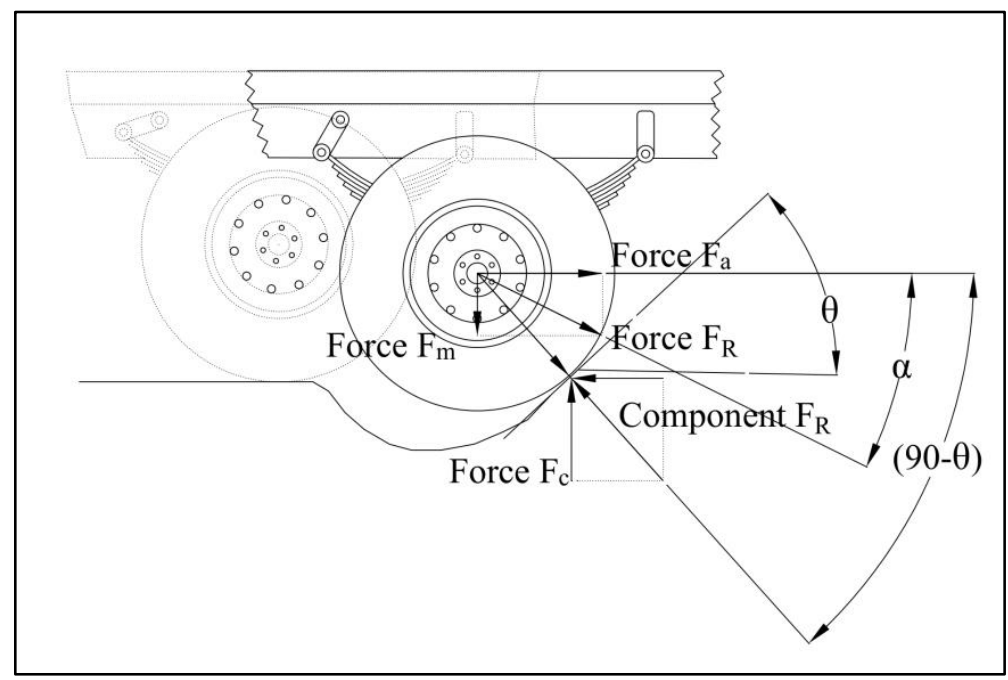

Figure 5 Forces representation for pothole

\subsubsection{Forces experienced by wheel}

Force acting on the wheel at point of contact is because of the component of force $F_{R}$, that is related to force due to vehicle acceleration, and also force due to the mass of the vehicle.

$$
F_{R}{ }^{\prime}=\mathrm{F}_{\mathrm{R}} * \cos (90-\theta-\alpha) \quad \text { Eq. } 7
$$

The force acting on the suspension $F_{C}$ is acted on the suspension of the vehicle. It has components of all the forces on the wheel and can be given by Eq. 6 .

$$
F_{C}=F_{R}{ }^{\prime} * \cos \theta
$$

\subsubsection{Height difference between either side of chassis}

The force acting on the suspension is deduced and with the known spring constant $k$, compression in spring can be calculated by,

$$
\begin{gathered}
C_{f}=\frac{F_{C}}{k} \\
h=C_{f}+y
\end{gathered}
$$

Eq. 10

\subsubsection{Roll angle due to pothole}

The height difference of two wheels on an axle is the sum of displacement of the wheel in ydirection into the pothole and compression of suspension because of forces acting on it. The roll angle is related to this height difference and track width of the vehicle as follows,

$$
\varnothing=\tan ^{-1}(h / B)
$$

Eq. 11 


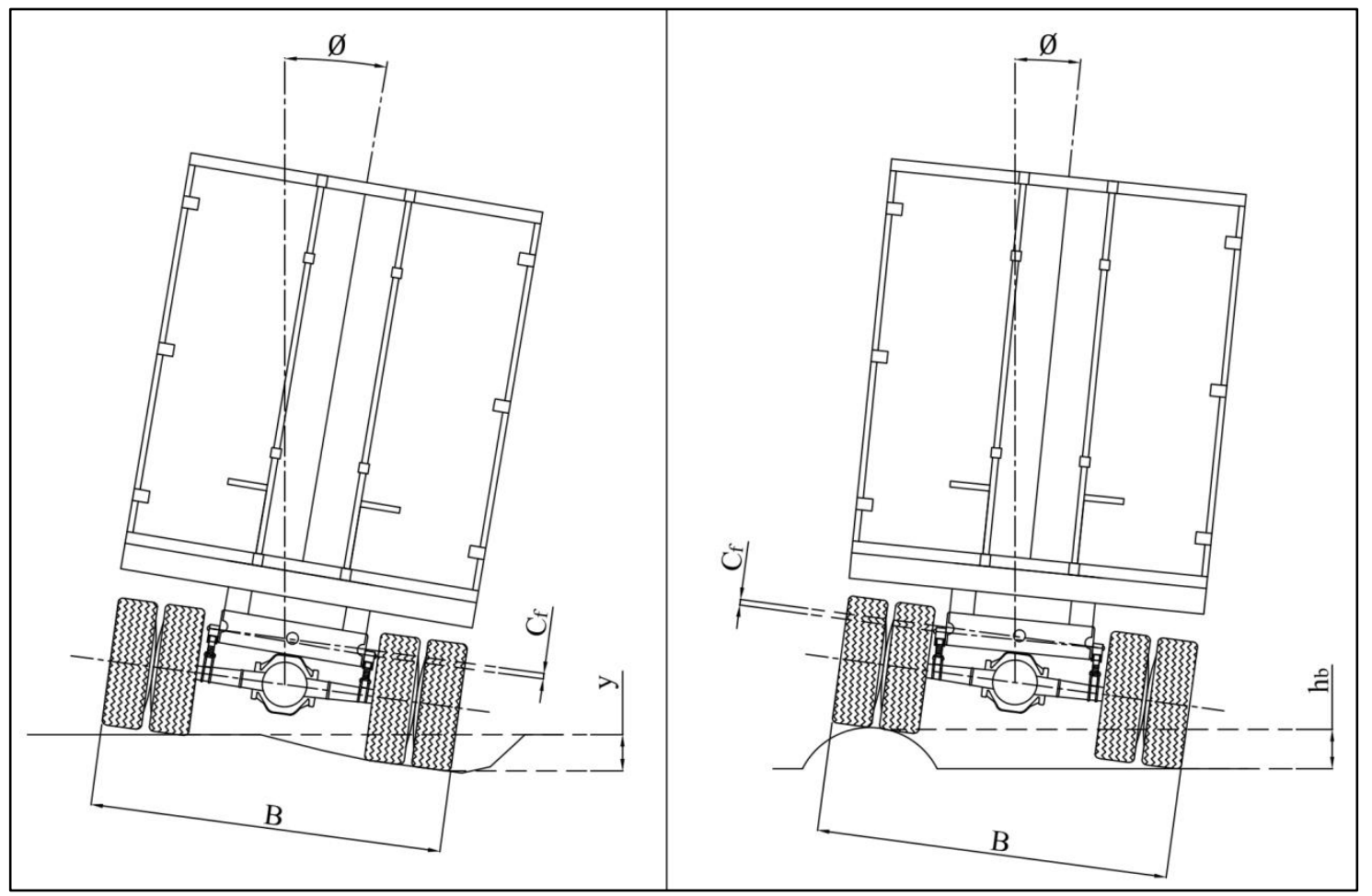

Figure 6 Height change relative to wheels due to road profile

\subsection{Interaction of the bump with the wheel}

Unlike the interaction of wheel with the pothole, the wheel always interacts with the bump irrespective of the velocity of the vehicle; in other words, the wheel will not skip bump at higher velocity. The point of contact of the wheel with the bump on road is necessary to calculate the forces on suspension. Height and the radius of the bump determine the point of contact; when bump height is increased the tangent angle at the point of contact increases. If the radius of the wheel is more, the angle of contact is steeper for the same bump height. Table 3 shows the estimation of the contact angle for different combinations of bump height, bump radius and radius of the wheel. Any value that is in between can be interpolated.

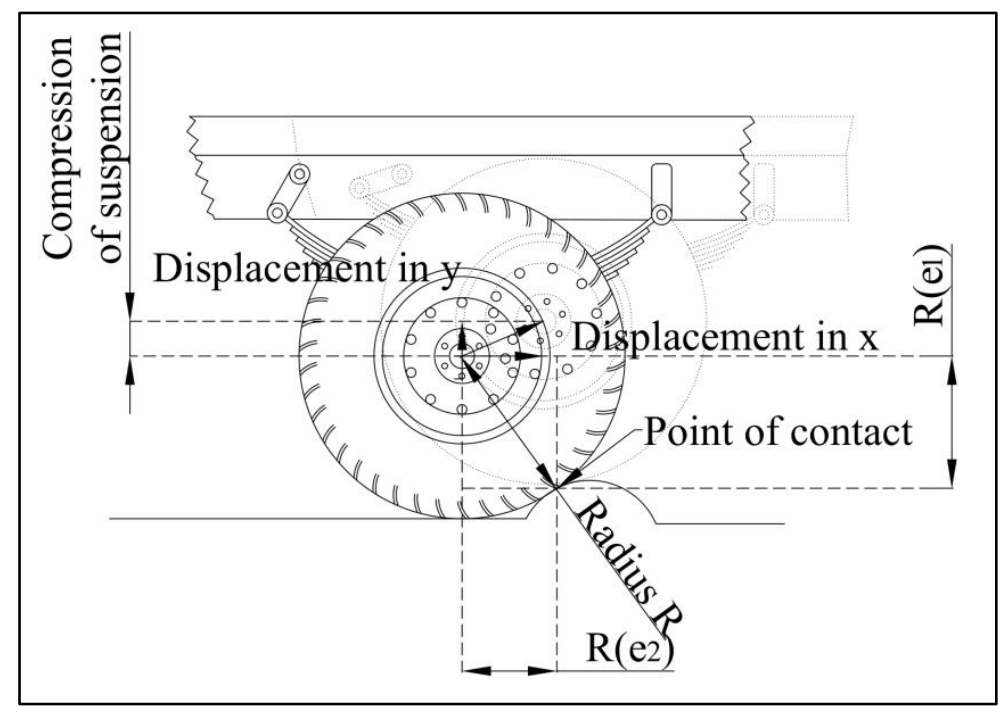

Figure 7 Point of contact for bump 
For the estimation, bumps that are only less than half the radius are assumed, as, if bump height exceeds more than that, it may act as an obstacle.

Table 3 estimation of point of contact for bump

\begin{tabular}{|c|c|c|c|c|c|c|}
\hline $\begin{array}{l}\text { S. } \\
\text { No. }\end{array}$ & $\begin{array}{l}\text { Radius of } \\
\text { bump }\end{array}$ & $\begin{array}{l}\text { Height of } \\
\text { bump }\end{array}$ & $\begin{array}{l}\text { Relation of the } \\
\text { bump to Radius of } \\
\text { wheel }\end{array}$ & $\begin{array}{c}\text { Angle } \\
\text { approximated }\end{array}$ & $\begin{array}{l}\text { Value of } \mathrm{e}_{1} \\
\text { (cosine } \\
\text { value) }\end{array}$ & $\begin{array}{l}\text { Value of } e_{2} \\
\text { (sine value) }\end{array}$ \\
\hline \multirow{3}{*}{1} & \multirow{3}{*}{$\mathrm{R}_{\mathrm{b}}$} & \multirow{3}{*}{$\mathrm{h}_{\mathrm{b}} \leq 1 / 3 \mathrm{R}_{\mathrm{b}}$} & $\mathrm{h}_{\mathrm{b}}=1 / 2 \mathrm{R}$ & 35 & 0.82 & 0.57 \\
\hline & & & $\mathrm{h}_{\mathrm{b}}=1 / 5 \mathrm{R}$ & 25 & 0.91 & 0.42 \\
\hline & & & $\mathrm{h}_{\mathrm{b}}=1 / 10 \mathrm{R}$ & 20 & 0.94 & 0.34 \\
\hline \multirow{3}{*}{2} & \multirow{3}{*}{$\mathrm{R}_{\mathrm{b}}$} & \multirow{3}{*}{$\begin{array}{c}1 / 3 \mathrm{R}_{\mathrm{b}}<\mathrm{h}_{\mathrm{b}} \\
\leq 2 / 3 \mathrm{R}_{\mathrm{b}}\end{array}$} & $\mathrm{h}_{\mathrm{b}}=1 / 2 \mathrm{R}$ & 43 & 0.73 & 0.68 \\
\hline & & & $\mathrm{h}_{\mathrm{b}}=1 / 5 \mathrm{R}$ & 30 & 0.87 & 0.50 \\
\hline & & & $\mathrm{h}_{\mathrm{b}}=1 / 10 \mathrm{R}$ & 22 & 0.93 & 0.37 \\
\hline \multirow{3}{*}{3} & \multirow{3}{*}{$\mathrm{R}_{\mathrm{b}}$} & \multirow{3}{*}{$\begin{array}{l}2 / 3 \mathrm{R}_{\mathrm{b}}<\mathrm{h}_{\mathrm{b}} \\
\quad \leq \mathrm{R}_{\mathrm{b}}\end{array}$} & $\mathrm{h}_{\mathrm{b}}=1 / 2 \mathrm{R}$ & 44 & 0.72 & 0.69 \\
\hline & & & $h_{b}=1 / 5 \mathrm{R}$ & 32 & 0.85 & 0.53 \\
\hline & & & $\mathrm{h}_{\mathrm{b}}=1 / 10 \mathrm{R}$ & 22 & 0.93 & 0.37 \\
\hline
\end{tabular}

To determine the point of contact, the fraction is multiplied to the radius in the y-direction, where the fraction is approximated cosine component of the radius. The position in $\mathrm{x}-$ direction need not be calculated as there exist two points for a known point of contact in the $y$-direction, and point closest to wheel can be taken as the point of contact. However, the relationship between the point of contact in $\mathrm{x}$ and $\mathrm{y}$ direction is given as,

$$
R^{2}=\left(R\left(e_{1}\right)\right)^{2}+\left(R\left(e_{2}\right)\right)^{2}
$$

The height of the point of contact from the ground can be determined by,

$$
\text { height of point of contact }=R-R\left(e_{1}\right)
$$

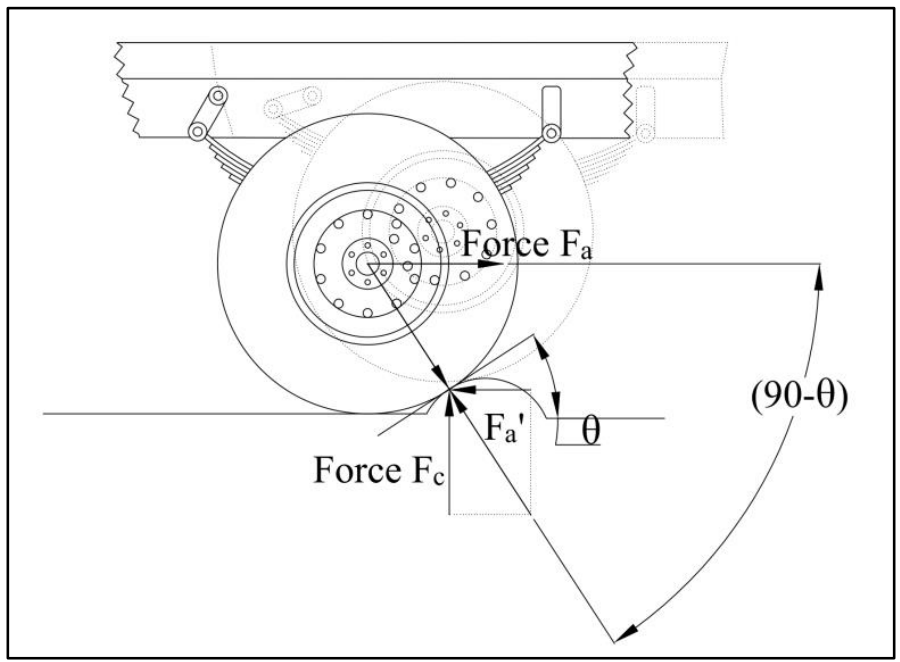

Figure 8 Forces representation for bump

Once the point of contact and angle of the tangent at the point of contact is known, forces on suspension can be calculated. However, because of the magnitude of forces exerted, the 
wheel can either stay in contact with road surface or lift-off. To determine this, an equation for y displacement is written.

Special case i:

For a step bump, the angle of the tangent at the point of contact can be given by the equation,

Special case ii:

$$
\theta=\cos ^{-1}\left(\frac{R-h_{b}}{R}\right)
$$

For a ramp, the angle of the tangent at the point of contact will be the same as the angle of the ramp.

\subsubsection{Forces experienced by suspension}

At the point of contact, the force exerted on the wheel is only because of the vehicle acceleration, the force due to mass is cancelled by the reaction force from the ground. Due to the force wheel experiences an impulse. The time of impulse, however, is unknown without experimentation. Literature exists for the interaction of wheel with different speed bumps, where recorded data provides the time of contact [11]. The time of impulse is taken as 0.1 second, which is an estimate and can vary slightly. From the momentum force relation, considering the impact force on the wheel, we have

$$
F * \Delta t=m * v
$$

The force at the point of contact will be a component of the force due to acceleration of the vehicle.

$$
\begin{array}{cc}
F_{a}{ }^{\prime}=F_{a} * \cos (90-\theta) & \text { Eq. } 16 \\
F_{C}=F_{a}{ }^{\prime} * \cos \theta & \text { Eq. } 17
\end{array}
$$

\subsubsection{Height difference between either side of chassis}

To get the height difference of the wheels of an axle, the maximum height that wheel encountering bump will lift-off should be known. If force magnitude is low the wheel can follow the profile of the road, but if force magnitude is high wheel can lift off the ground.

The force, $F_{C}$ will impart velocity to wheel in the y-direction and due to damping of suspension, some force is lost. The remainder of the force will then act on the vehicle. So, if $F_{C}$ is large enough to overcome the spring force and force due to mass of the vehicle, can it lift the vehicle off the ground. The total force experienced by vehicle after spring compression and overcoming acceleration due to gravity acting constantly on the vehicle can be given by,

$$
F_{C}-k C_{m}-F_{m}
$$

If the force value is negative, the wheel follows the bump profile. If it is zero or positive, the suspension is compressed completely and chassis also experiences the force. 
At maximum height, the kinetic energy of wheel is converted to potential energy and we get,

$$
h=\frac{M * u^{2}}{2\left(F_{C}-k C_{m}-F_{m}\right)}
$$

Proof: By equating kinetic energy and potential energy $\frac{1}{2} m v^{2}=m g h$ mass times acceleration due to gravity can be replaced by force required to raise object to height, $\frac{1}{2} m v^{2}=F h$

Rewriting terms in equation, $h=\frac{m v^{2}}{2 F}$

The maximum lift-off height above bump can be given from above Eq.15 and Eq. 19 as,

$$
h=\left\{\begin{array}{cl}
\left(\frac{0.01 F_{C}{ }^{2}}{2 M\left(F_{C}-k C_{m}-F_{m}\right)}\right), & \text { If Eq. } 15 \text { is positive } \\
\left(h_{b}\right), & \text { If } F_{C} \ll k C_{m} \\
\left(h_{b}-\frac{F_{c}}{k}\right), & \text { If } F_{C} \leq k C_{m}
\end{array}\right.
$$

\subsubsection{Roll angle due to bump}

The rise in height of vehicle due to bump is related to roll as follows,

\subsection{Lean-over distance due to roll}

$$
\emptyset=\tan ^{-1}(h / B)
$$

The roll angle is estimated based on the forces experienced by the suspension separately for pothole and bump.

The roll angle relates to lean-over distance based on how tall the vehicle is

\section{Discussion}

$$
S=\sin \emptyset * A
$$

Eq. 22

The lean-over distance, once estimated can tell the proximity to be provided to the side of a tall vehicle to avoid a collision when vehicle is moving on an uneven road surface. If two tall vehicles are moving alongside each other, the lean-over distances of both the vehicles should be considered and the gap equal to the sum of the individual lean-over distances should be provided when steering, to avoid a collision.

The equations can be used as a base to build an autonomous vehicle safety system that considers the collision due to the roll of the vehicle.

\section{Conclusion}

Possibility of a collision between tall vehicles due to roll when they are moving on an uneven road is proposed. The motion of wheel due to uneven road profile is presented distinctly. The possible types of uneven road are illustrated and a mathematical estimation of roll angle in each case is interpreted. Roll angle is mathematically related to vehicle speed, weight, and 
road profile. The lean-over distance calculated from the roll angle can be used to identify the required proximity to steer a tall vehicle on an uneven road.

Additionally, the work can be implemented in an algorithmic form in an actual autonomous vehicle to see how the roll angle and lean-over distance estimation works in a real-world scenario. Also, work can be extended to consider wheel compliance into the equations. Interaction of vehicle and roll angle for different bump profiles can also be studied.

\section{References}

[1] P. Li, T. Qin, S. Shen, Stereo Vision-Based Semantic 3D Object and Ego-Motion Tracking for Autonomous Driving, Lect. Notes Comput. Sci. (Including Subser. Lect. Notes Artif. Intell. Lect. Notes Bioinformatics). 11206 LNCS (2018) 664-679. https://doi.org/10.1007/978-3-030-01216-8_40.

[2] Y. Weber, S. Kanarachos, The correlation between vehicle vertical dynamics and deep learning-based visual target state estimation: A sensitivity study, Sensors (Switzerland). 19 (2019). https://doi.org/10.3390/s19224870.

[3] D. González, J. Pérez, V. Milanés, F. Nashashibi, A Review of Motion Planning Techniques for Automated Vehicles, IEEE Trans. Intell. Transp. Syst. 17 (2016) 11351145. https://doi.org/10.1109/TITS.2015.2498841.

[4] C. Katrakazas, M. Quddus, W.H. Chen, L. Deka, Real-time motion planning methods for autonomous on-road driving: State-of-the-art and future research directions, Transp. Res. Part C Emerg. Technol. 60 (2015) 416-442. https://doi.org/10.1016/j.trc.2015.09.011.

[5] B. Kim, D. Kim, S. Park, Y. Jung, K. Yi, Automated Complex Urban Driving based on Enhanced Environment Representation with GPS/map, Radar, Lidar and Vision, IFAC-PapersOnLine. 49 (2016) 190-195. https://doi.org/10.1016/j.ifacol.2016.08.029.

[6] I. Blekhman, E. Kremer, Vertical-longitudinal dynamics of vehicle on road with unevenness, in: Procedia Eng., 2017. https://doi.org/10.1016/j.proeng.2017.09.361.

[7] H.D. and B.Z. Boyuan Li, Path Planning for Autonomous Vehicle in Off-Road Scenario, in: Umar Zakir Abdul Hamid; Volkan Sezer; Bin Li (Ed.), Path Plan. Auton. Veh. - Ensuring Reliab. Driverless Navig. Control Maneuver, IntechOpen, 2019. https://doi.org/10.5772/intechopen.85384.

[8] E.L. Ding, T. Massel, Estimation of vehicle roll angle, IFAC Proc. Vol. 38 (2005) 122-127. https://doi.org/10.3182/20050703-6-cz-1902.01908.

[9] M.R. Seyedi, S. Jung, G. Dolzyk, J. Wekezer, Experimental assessment of vehicle performance and injury risk for cutaway buses using tilt table and modified dolly rollover tests, Accid. Anal. Prev. 132 (2019). https://doi.org/10.1016/j.aap.2019.105287.

[10] T.R. Botha, P. Schalk Els, Rough terrain profiling using digital image correlation, J. Terramechanics. 59 (2015) 1-17. https://doi.org/10.1016/j.jterra.2015.02.002.

[11] H. Taghavifar, A. Modarres Motlagh, A. Mardani, A. Hassanpour, A. Haji Hosseinloo, C. Wei, The induced shock and impact force as affected by the obstacle geometric 
factors during tire-obstacle collision dynamics, Meas. J. Int. Meas. Confed. 84 (2016) 47-55. https://doi.org/10.1016/j.measurement.2016.02.003. 